\title{
Predicting Biological Cleanliness: An Empirical Bayes Approach for Spacecraft Bioburden Accounting
}

Andrei V Gribok, J. Nick Benardini, Arman Seuylemezian

March 2020

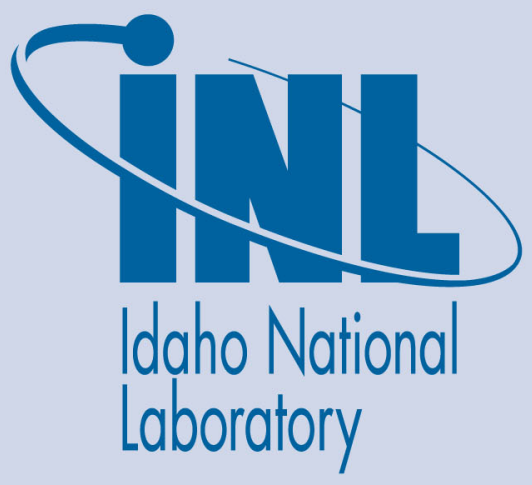

The INL is a U.S. Department of Energy National Laboratory operated by Battelle Energy Alliance 


\title{
Predicting Biological Cleanliness: An Empirical Bayes Approach for Spacecraft Bioburden Accounting
}

\author{
Andrei V Gribok, J. Nick Benardini, Arman Seuylemezian
}

March 2020

Idaho National Laboratory Idaho Falls, Idaho 83415

http://www.inl.gov

Prepared for the U.S. Department of Energy Office of Nuclear Energy Under DOE Idaho Operations Office

Contract DE-AC07-05ID14517 
Predicting Biological Cleanliness: An Empirical Bayes Approach for Spacecraft Bioburden Accounting

J. Nick Benardini ${ }^{1}$, Andrei Gribok ${ }^{2}$, Arman Seuylemezian ${ }^{1}$

${ }^{1}$ California Institute of Technology, Jet Propulsion Laboratory

${ }^{2}$ Idaho National Laboratory

2020 IEEE Aerospace Conference

Big Sky Montana

March 9, 2020 


\section{Agenda}

- Biological Cleanliness Verification

- Biological Verification Overview

- Direct Spacecraft Verification

- Direct Verification Count Distribution

- Bioburden Accounting Evolution

- Gamma-Poisson Compound Distribution Model

- Summary of Bioburden InSight Components

- Results and Discussion

- Summary

- Future Work 


\section{Biological Cleanliness Verification}

- How does one calculate spore requirements from observed, direct spacecraft sampling events?

- Directly addresses requirement reporting

- Mars

- $5 \times 10^{5}$ spores per launched spacecraft

- $3 \times 10^{5}$ spores per landed

- <300 spores/m2

- Outer planets

- Inadvertent contamination of an ocean or other liquid water body to less than a probability of $1 \times 10^{-4}$ per mission.

- NASA or ESA Standard Spore assay for direct hardware verification - damp water wipe or swabs from hardware surfaces during mandatory inspection points. 


\section{Biological Verification Overview}

\section{Typical Spacecraft Subsystem Process Flow}
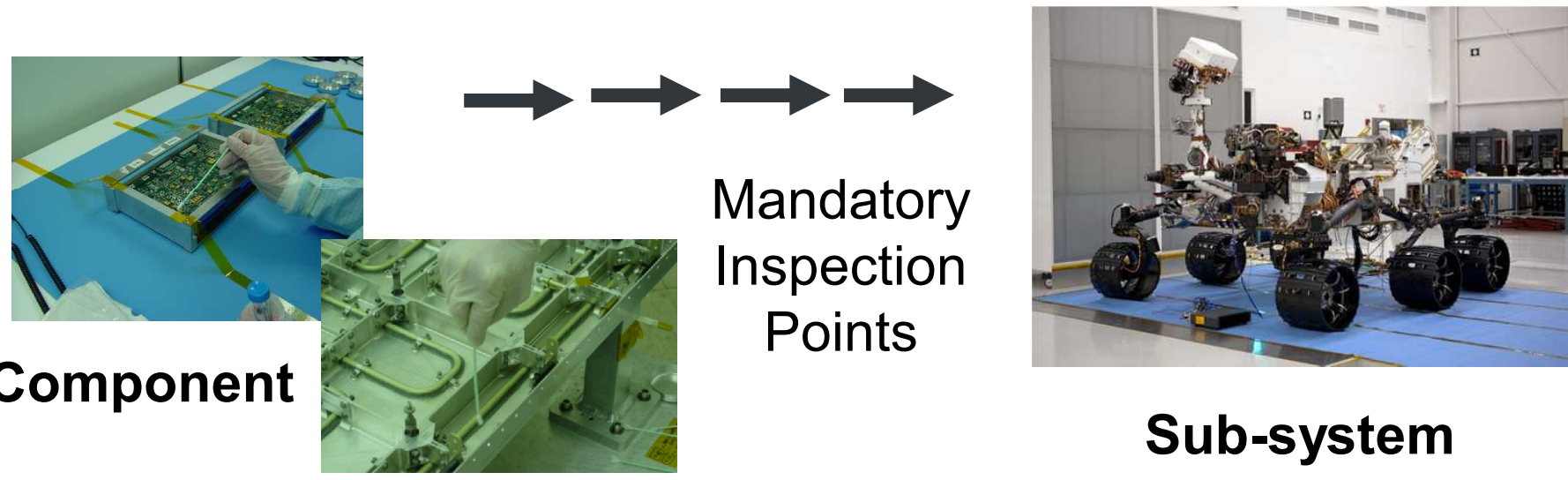

Sub-system

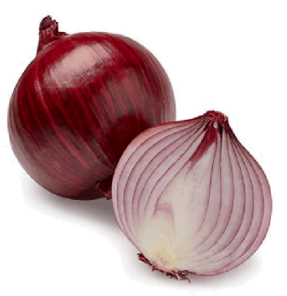

Mandatory Inspection Points

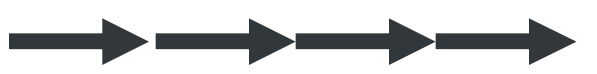

\section{System During I\&T}

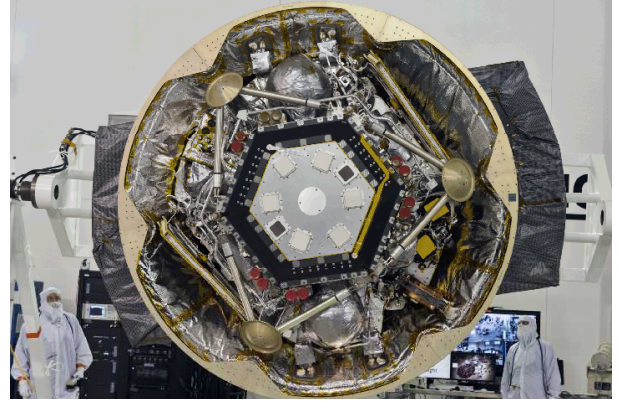

Image Credit:

https://www.flickr.com/people/nasakennedy

\section{System During Launch Ops}

\author{
Mandatory \\ Inspection Points
}

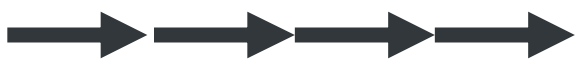




\section{Direct Spacecraft Verification}

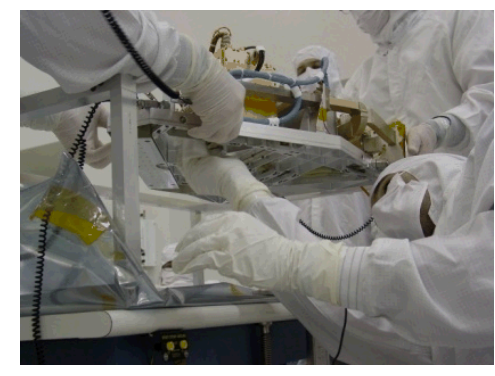

Clean hardware (and table or bag) with IPA wipe prior to sample or install
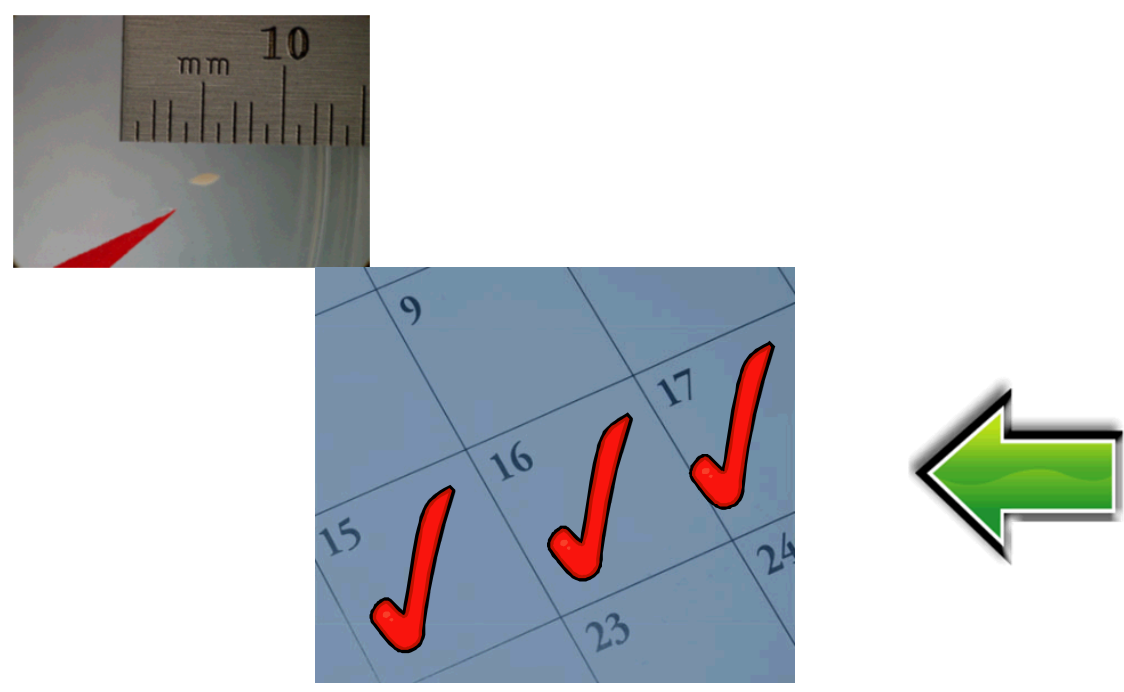

Count Plates for Colony Forming Units (CFU) @ 24h, 48h, and 72h

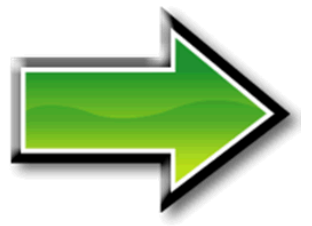

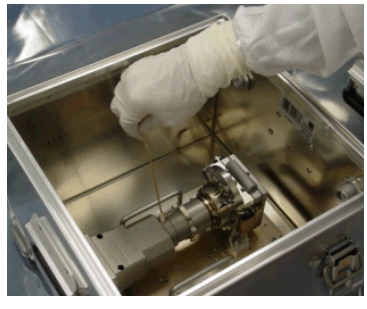

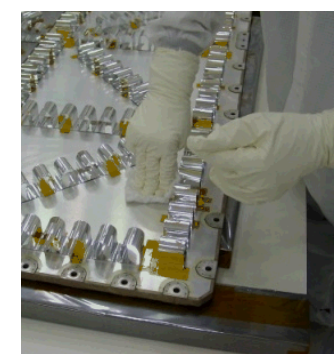

Assay Swab or Wipe (water is used as solvent)

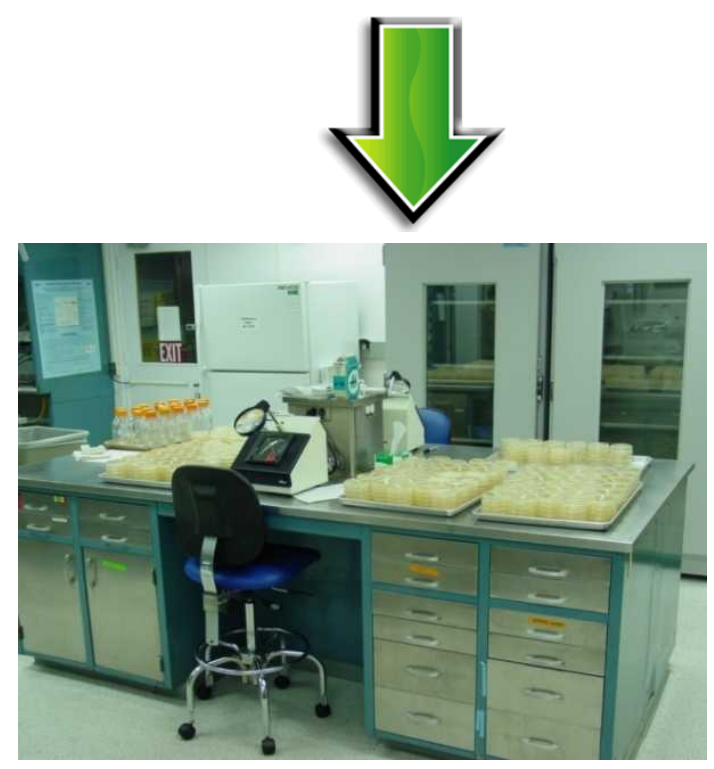

Process swabs and wipes, $\sim 3$ hours required post-assay 


\section{Direct Verification Counts Distribution}

- Bayesian statistics suited dataset similar to that of nuclear industry

- Data rich with many data points that occur at low frequency

- $>80 \%$ of wipes and $>90 \%$ of swabs containing a bioburden count of 0

- $\quad>85 \%$ of a missions petri dish observations $=$ no colony forming units

Swab 72 Hour Counts

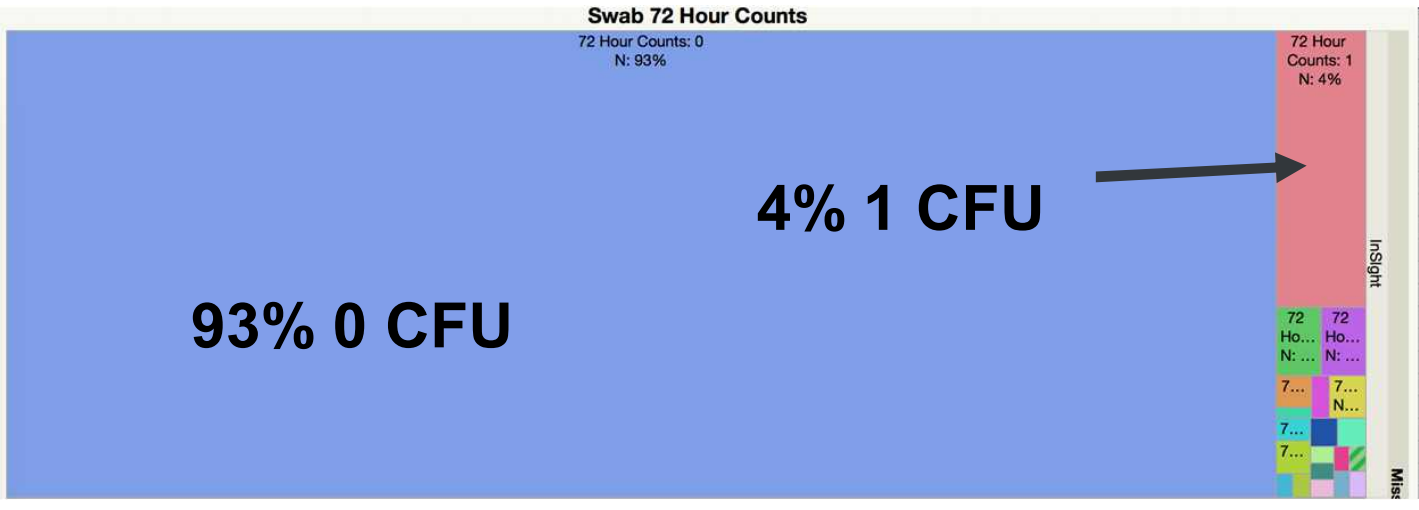

\begin{tabular}{|c|c|c|c|}
\hline & MER (Both) & MSL & InSight \\
\hline Swabs & 3,066 & 3,472 & 1,983 \\
\hline Wipes & 529 & 1,283 & 1,127 \\
\hline Plates (Equivalent) & 25,489 & 47,997 & 39,379 \\
\hline Counting Opportunities & 76,467 & 143,991 & 118,137 \\
\hline
\end{tabular}




\section{Bioburden Accounting for Mars Landed Spacecraft Raw Spore Counts to Calculated Bioburden}

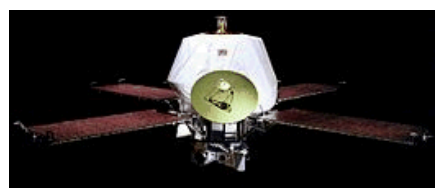

NASA / Artist Illustration
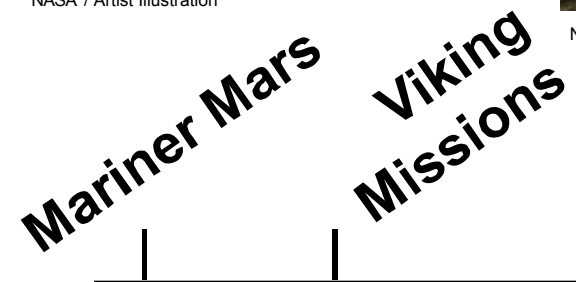

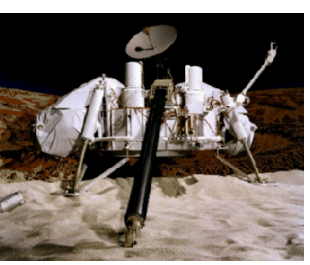

NASA / Arisit IIlustration

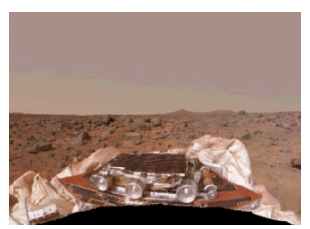

NASA

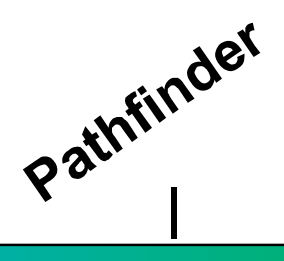

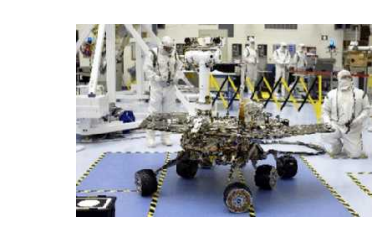

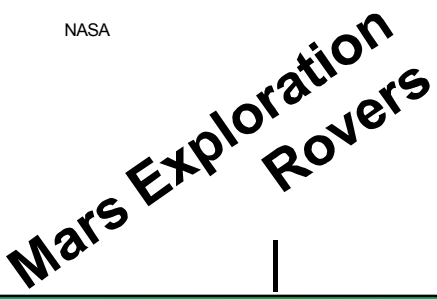

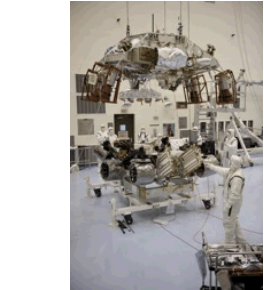

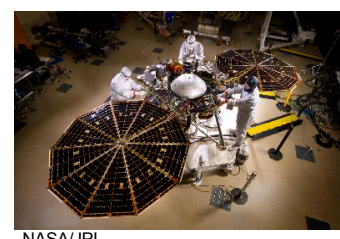

NASAJJPL-
Caltech/Lockheed
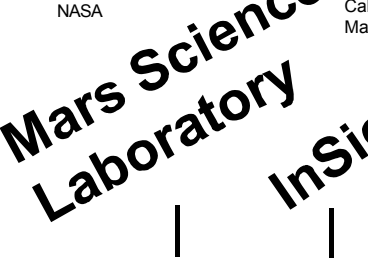

2010

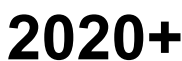

the total area represented by a group or sample set, $\mathrm{m}^{2}$

the total number of swabs or wipes

the total number of samples

is the area sampled by the $\mathrm{i}^{\text {th }}$ swab and the $\mathrm{j}^{\text {th }}$ wipe, $\left(\mathrm{m}^{2}\right)$

the pour fractions for swabs and wipes

the recovery efficiencies for swabs and wipes the total effective area, $\left(m^{2}\right)$

the number of CFU counted in the $i^{\text {th }}$ swab sample the number of CFU counted in the $\mathrm{j}^{\text {th }}$ wipe sample

the total number of CFU in a group, (spores $/ \mathrm{m}^{2}$ )
Poisson and Gaussian

Statistics

Examples equations utilized:

$$
\begin{gathered}
\sigma=1 \div\left(\mathbf{A}_{0} \mathbf{A}_{s}\right) \\
B_{\text {max }}=\mathbf{1} / A_{s}+3 \sigma \\
\sigma=1 \div \mathbf{A}_{s} \\
B_{\text {max }}=\mathbf{1} / A_{s}+3 \sigma \\
\sigma=\sqrt{ }\left(\mathbf{N} / \mathbf{A}_{s}\right) \\
B_{\text {max }}=N / A_{s}+3 \sigma
\end{gathered}
$$




\section{Gamma-Poisson Bioburden Compound Distribution Model}

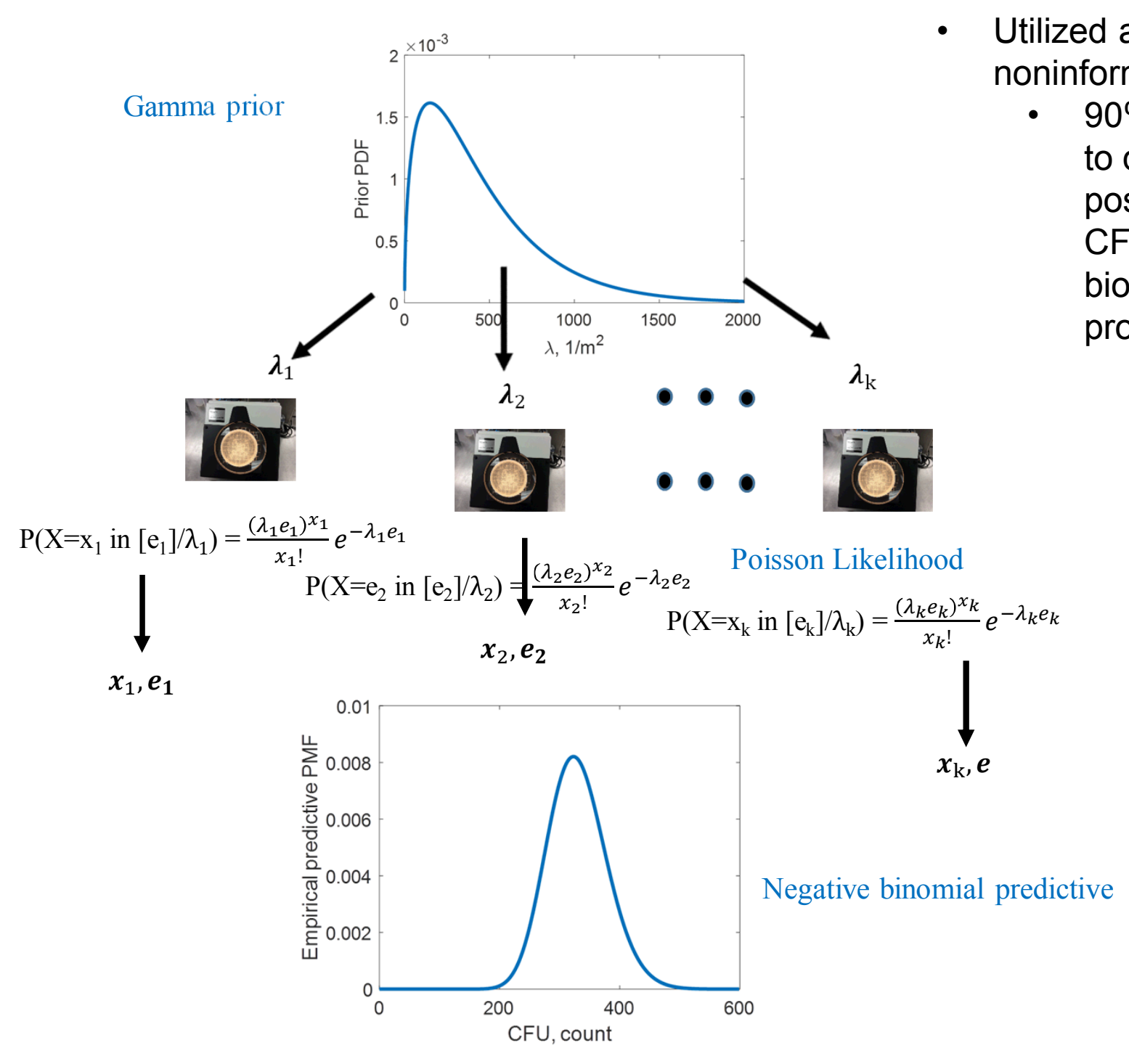




\section{Summary of Bioburden InSight Components}

Bounding Cases for Evaluation

\begin{tabular}{|cccccc|} 
Component & $\begin{array}{c}\text { CFU } \\
\text { count }\end{array}$ & $\begin{array}{c}\text { Area } \\
\text { sampled, } \\
\mathbf{m}^{\mathbf{2}}\end{array}$ & $\begin{array}{c}\text { Exposure: } \\
\text { area sampled } \\
\times \text { pour ratio, } \\
\mathbf{m}^{\mathbf{2}}\end{array}$ & $\begin{array}{c}\text { Total surface } \\
\text { area of the } \\
\text { component, } \\
\mathbf{m}^{\mathbf{2}}\end{array}$ & $\begin{array}{c}\% \\
\text { sampled=area } \\
\text { sampled/total } \\
\text { area }\end{array}$ \\
\hline $\mathbf{9}$ & 0 & 0.6031 & 0.2167 & 0.7580 & 79.5650 \\
\hline $\mathbf{7 3}$ & 0 & 2.4200 & 0.6160 & 2.7400 & 88.3212 \\
\hline $\mathbf{3 0 0}$ & 1 & 2.6600 & 0.6705 & 5.0000 & 53.2000 \\
\hline $\mathbf{1 6 9}$ & 1 & 0.2400 & 0.1920 & 0.5850 & 41.0260 \\
\hline $\mathbf{2 8 3}$ & 5 & 4.5710 & 1.1427 & 12.0000 & 38.0920 \\
\hline $\mathbf{2 4 3}$ & 5 & 0.2800 & 0.1140 & 0.2980 & 93.9600 \\
\hline $\mathbf{3 8}$ & 12 & 3.1050 & 0.8065 & 10.0000 & 31.0500 \\
\hline $\mathbf{2 6 1}$ & 52 & 0.0600 & 0.0480 & 0.3120 & 19.2310 \\
\hline
\end{tabular}




\section{Summary of posterior and predictive inference for components $9,73,300$}

\begin{tabular}{|l|c|c|c|c|c|c|}
$\begin{array}{c}\text { Prior } \\
\text { distribution }\end{array}$ & $\begin{array}{c}\text { Posterior mean. } \\
\text { Bioburden } \\
\text { density }-\lambda, \\
\text { CFU/m² }\end{array}$ & $\begin{array}{c}5^{\text {th }} \text { percentile } \\
\text { of posterior } \\
\text { distribution }\end{array}$ & $\begin{array}{c}\mathbf{9 5}^{\text {th }} \\
\text { percentile of } \\
\text { posterior } \\
\text { distribution }\end{array}$ & $\begin{array}{c}\text { Predictive } \\
\text { mean, } \\
\text { CFU }\end{array}$ & $\begin{array}{c}5^{\text {th }} \text { percentile } \\
\text { of predictive } \\
\text { distribution }\end{array}$ & $\begin{array}{c}9^{\text {th }} \text { percentile } \\
\text { of predictive } \\
\text { distribution }\end{array}$ \\
\hline CNI & 2.2889 & 0.0090 & 8.7928 & 1.7350 & 0 & 7 \\
\hline MOM & 0.7603 & $4.1117 \mathrm{e}-08$ & 4.0993 & 0.5763 & 0 & 3 \\
\hline
\end{tabular}

73

\begin{tabular}{|l|c|c|c|c|c|c|}
$\begin{array}{c}\text { Prior } \\
\text { distribution }\end{array}$ & $\begin{array}{c}\text { Posterior mean. } \\
\text { Bioburden } \\
\text { density }-\Lambda, \\
\text { CFU/m2 }\end{array}$ & $\begin{array}{c}5^{\text {th }} \text { percentile } \\
\text { of posterior } \\
\text { distribution }\end{array}$ & $\begin{array}{c}\mathbf{9 5}^{\text {th }} \\
\text { percentile of } \\
\text { posterior } \\
\text { distribution }\end{array}$ & $\begin{array}{c}\text { Predictive } \\
\text { mean, } \\
\text { CFU }\end{array}$ & $\begin{array}{c}5^{\text {th }} \text { percentile } \\
\text { of predictive } \\
\text { distribution }\end{array}$ & $\begin{array}{c}\mathbf{9 5}^{\text {th }} \text { percentile } \\
\text { of predictive } \\
\text { distribution }\end{array}$ \\
\hline CNI & 0.8094 & 0.0031 & 3.1096 & 2.2180 & 0 & 9 \\
\hline MOM & 0.2684 & $1.4519 \mathrm{e}-08$ & 1.4475 & 0.7356 & 0 & 4 \\
\hline
\end{tabular}

300

\begin{tabular}{|l|c|c|c|c|c|c|}
$\begin{array}{c}\text { Prior } \\
\text { distribution }\end{array}$ & $\begin{array}{c}\text { Posterior mean. } \\
\text { Bioburden } \\
\text { density }-\lambda, \\
\text { CFU/m2 }\end{array}$ & $\begin{array}{c}5^{\text {th }} \text { percentile } \\
\text { of posterior } \\
\text { distribution }\end{array}$ & $\begin{array}{c}\mathbf{9 5}^{\text {th }} \\
\text { percentile of } \\
\text { posterior } \\
\text { distribution }\end{array}$ & $\begin{array}{c}\text { Predictive } \\
\text { mean, } \\
\text { CFU }\end{array}$ & $\begin{array}{c}5^{\text {th }} \text { percentile } \\
\text { of predictive } \\
\text { distribution }\end{array}$ & $\begin{array}{c}\mathbf{9 5}^{\text {th }} \text { percentile } \\
\text { of predictive } \\
\text { distribution }\end{array}$ \\
\hline CNI & 2.2315 & 0.2617 & 5.8130 & 11.1579 & 1 & 30 \\
\hline MOM & 1.7355 & 0.1267 & 4.9272 & 8.6778 & 0 & 26 \\
\hline
\end{tabular}




\section{Summary of posterior and predictive inference for components 169, 283, 243}

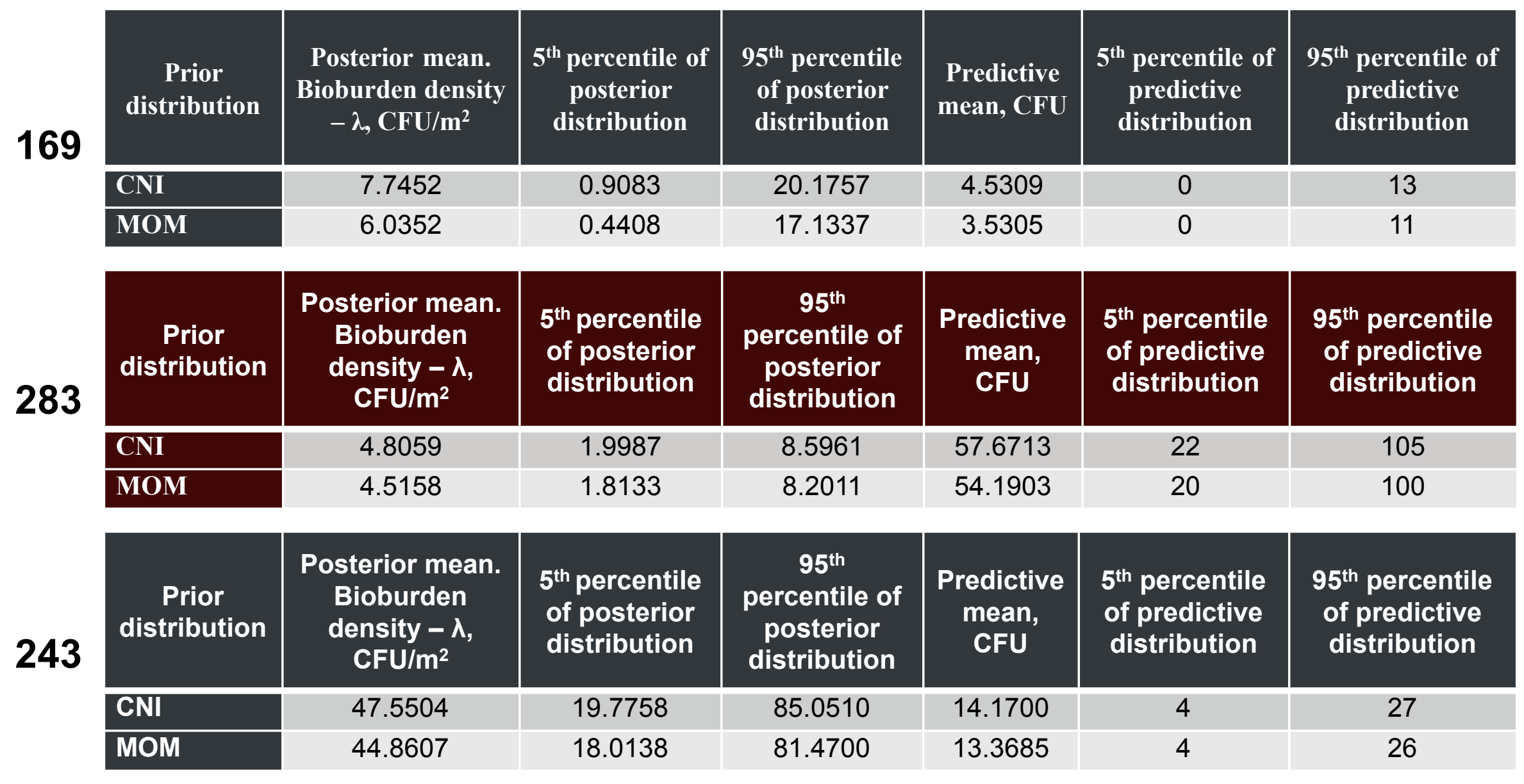




\section{Summary of posterior and predictive inference for components 38, 261}

38

\begin{tabular}{|l|c|c|c|c|c|c|}
$\begin{array}{c}\text { Prior } \\
\text { distribution }\end{array}$ & $\begin{array}{c}\text { Posterior mean. } \\
\text { Bioburden density } \\
-\lambda, \mathbf{C F U} / \mathbf{m}^{2}\end{array}$ & $\begin{array}{c}\mathbf{5}^{\text {th }} \text { percentile of } \\
\text { posterior } \\
\text { distribution }\end{array}$ & $\begin{array}{c}\mathbf{9 5}^{\text {th }} \text { percentile } \\
\text { of posterior } \\
\text { distribution }\end{array}$ & $\begin{array}{c}\text { Predictive } \\
\text { mean, CFU }\end{array}$ & $\begin{array}{c}\mathbf{5}^{\text {th }} \text { percentile of } \\
\text { predictive } \\
\text { distribution }\end{array}$ & $\begin{array}{c}\mathbf{9 5}^{\text {th }} \text { percentile of } \\
\text { predictive } \\
\text { distribution }\end{array}$ \\
\hline CNI & 15.4671 & 9.0398 & 23.2949 & 154.6710 & 88 & 236 \\
\hline MOM & 15.0630 & 8.7294 & 22.7980 & 150.6308 & 85 & 231 \\
\hline
\end{tabular}

261

\begin{tabular}{|l|c|c|c|c|c|c|}
$\begin{array}{c}\text { Prior } \\
\text { distribution }\end{array}$ & $\begin{array}{c}\text { Posterior mean. } \\
\text { Bioburden } \\
\text { density } \mathbf{A}, \\
\text { CFU/m }\end{array}$ & $\begin{array}{c}\mathbf{5}^{\text {th }} \text { percentile } \\
\text { of posterior } \\
\text { distribution }\end{array}$ & $\begin{array}{c}\mathbf{9 5}^{\text {th }} \\
\text { percentile of } \\
\text { posterior } \\
\text { distribution }\end{array}$ & $\begin{array}{c}\text { Predictive } \\
\text { mean, } \\
\text { CFU }\end{array}$ & $\begin{array}{c}\mathbf{5}^{\text {th }} \text { percentile } \\
\text { of predictive } \\
\text { distribution }\end{array}$ & $\begin{array}{c}\mathbf{9 5}^{\text {th }} \text { percentile } \\
\text { of predictive } \\
\text { distribution }\end{array}$ \\
\hline CNI & 1057.0469 & 829.0645 & 1307.8988 & 329.7986 & 253 & 414 \\
\hline MOM & 1061.3672 & 831.7609 & 1314.0833 & 331.1465 & 254 & 416 \\
\hline
\end{tabular}




\section{Bioburden Density Comparison}

\begin{tabular}{|c|c|c|c|c|}
\hline & \multicolumn{2}{|c|}{ Proposed Bayesian Approach } & $\begin{array}{l}\text { MSL-based } 3 \\
\text { sigma (NASA }\end{array}$ & $\begin{array}{l}\text { InSight-based weighted } \\
\text { average technique }\end{array}$ \\
\hline Component & $\begin{array}{c}\text { CNI, Posterior } \\
\text { Mean Bioburden } \\
\text { Density }-\lambda, \\
\text { CFU } / \mathrm{m}^{2}\end{array}$ & $\begin{array}{c}\text { MOM, Posterior } \\
\text { Mean Bioburden } \\
\text { Density }-\lambda, \\
\text { CFU/m2 }\end{array}$ & $\begin{array}{l}3 \text { sigma Bioburden } \\
\text { Density }-\lambda, C F U / m^{2}\end{array}$ & $\begin{array}{c}\text { Weighted Average } \\
\text { Bioburden Density }-\lambda, \\
\text { CFU } / \mathrm{m}^{2}\end{array}$ \\
\hline 9 & 2.2889 & 0.7603 & 13.84 & 27.99 \\
\hline 73 & 0.8094 & 0.2684 & 4.87 & 17.36 \\
\hline 300 & 2.2315 & 1.7355 & 5.96 & 9.54 \\
\hline 169 & 7.7452 & 6.0352 & 20.83 & 33.70 \\
\hline 283 & 4.8059 & 4.5158 & 5.17 & 11.11 \\
\hline 243 & 47.5504 & 44.8607 & 130.14 & 186.70 \\
\hline 38 & 15.4671 & 15.0630 & 52.06 & 9.66 \\
\hline 261 & 1057.0469 & 1061.3672 & 2349.53 & 658.47 \\
\hline
\end{tabular}




\section{Summary}

- The mean values of predictive distribution are correlated with the total CFU count found on the component

- In general, the uncertainty in the posterior estimate of the bioburden density depends on the number of counts and sampled area, while the uncertainty in the predictive inference depends on sampling percentage.

- Bayes Factor approach is indicative of reliance on the data rather than on the prior for the components with larger counts

- Implementing a Bayesian statistical approach to perform bioburden density estimations will:

1. facilitate the application of historical datasets and engineering judgement in estimating the total bioburden and bioburden density;

2. assign appropriate confidence intervals and account for uncertainty using a methodological approach; and

3. allow for the prediction of bioburden throughout the lifecycle of a project.

- Future work to include

- Hierarchical Bayes being the subject of future work and model validation

- Develop informed priors based on hardware and reporting use cases

- Expansion of statistical approach to account for complete bioburden reporting of direct, implied and specification value hardware groups. 


\section{Abstract}

To comply with the international planetary protection policy set forth by the Committee on Space Research and NASA Agency level requirements, spacecraft destined to biologically sensitive planetary bodies have to minimize terrestrial biological contamination. Analysis, testing and inspection are the standard forward verification activities that are used to demonstrate compliance with the biological contamination requirements. For testing of spacecraft surface areas, a swab or wipe sample is collected from surfaces prior to last access and subsequently processed in the lab using NASA Approved Planetary Protection Methods for Culture Based Assays. Raw data resulting from this assay is then statistically treated employing a mathematical paradigm stemming from the 1970's Viking Lander Project to generate the bioburden density and total microbial bioburden present. This standard approach arbitrarily accounts for error and provides an upper conservative bound as it reports the maximum number of spores estimated to be present on flight hardware surfaces. A bioburden density estimate factors in the following variables: the observed bioburden count, representative volume processed, sampling efficiencies. Notably, to account for error in the approach, a 0 observed count is arbitrarily changed to a count of 1 for each hardware grouping.

The data generated by spacecraft bioburden verification campaigns in the past have resulted in $<80 \%$ of wipes and $<90 \%$ of swabs containing a bioburden count of 0 . As such, having a robust and well documented statistical approach for dealing with the probability of low incident rates is necessary to be able to estimate spacecraft bioburden. Being able to statistically describe the bioburden distribution and associated confidence level is a gamechanger for the development of bioburden allocations during mission design and will allow for tighter management of risk throughout spacecraft build. Thus, Empirical Bayes statistical approach was evaluated to estimate the microbial bioburden on spacecraft to mitigate the aforementioned mathematical concerns and provide a probabilistic bioburden distribution of the flight hardware surface.

For application of this approach to performing bioburden calculations, a range of non-informative prior assumptions on hardware surfaces are explored for Bayesian analyses while informative priors using posterior distributions from prior assays are utilized for Empirical Bayes analyses. Several non-informative priors are currently under investigation to assess fitness including use of these priors to serve as a foundation to build off of NASA specification values or a basis of risk to account for unknowns during the integration and testing process. Informative priors under consideration are generated using sampled bioburden values from hardware originating within like processing environments (e.g. vendor cleaning process or similar assembly process), temporal spacecraft status events as a prediction for hardware cleanliness of future samples, and heritage system bioburden actuals to predict allocation for subsequent missions. Informative priors and probabilistic bioburden distributions are then validated using data sets from the Mars Exploration Rover, Mars Science Laboratory, and InSight missions. Using Empirical Bayes approach to generate a probabilistic bioburden distribution as demonstrated through mission use cases provides a valid approach for use in the end-to-end requirements verification process. 


$$
\text { jpl.nasa.gov }
$$

